\title{
Long-term follow-up after laparoscopic management of endometrial cancer: a 15-year cohort study
}

\author{
Benoit Rabischong • Demetrio Larraín • Guillaume Le Bouëdec • Michel Canis • \\ Christophe Pomel • Kris Jardon • Fabrice Kwiatkowski • Jean-Louis Achard • \\ Jacques Dauplat • Gerard Mage
}

Received: 29 December 2010 / Accepted: 6 January 2011 / Published online: 28 January 2011

(C) Springer-Verlag 2011

\begin{abstract}
The objective of this study was to evaluate longterm oncological outcomes of laparoscopic management of endometrial carcinoma (EC) in a large series of consecutive patients from two referral cancer centres. The study is a large retrospective study with 15 -year follow-up. The clinical records of 207 consecutive women with clinical stage I EC managed by laparoscopy between 1990 and 2005 were reviewed. Laparoscopy included peritoneal washing, inspection of abdominal cavity, total laparoscopic hysterectomy + bilateral salpingo-oophorectomy and pelvic/para-aortic lymphadenectomy depending on the preoperative histology or frozen section results. Data collected included conversion rate, operative time, hospital stay, surgical complications, FIGO 1988 stage and 5-year survival. Laparoscopic procedures were converted to laparotomy in nine $(4.3 \%)$ cases. Mean operative time was $173.2 \mathrm{~min}$ (70-300 min). Mean
\end{abstract}

B. Rabischong $\cdot$ D. Larraín $\cdot$ M. Canis $\cdot$ K. Jardon $\cdot$ G. Mage Department of Obstetrics-Gynecology and Human Reproduction, CHU Estaing,

1 Place Lucie Aubrac,

63003 Clermont-Ferrand, France

G. Le Bouëdec $\cdot$ C. Pomel $\cdot$ J.-L. Achard $\cdot$ J. Dauplat Department of Gynecologic Oncology and Surgery,

Jean Perrin Cancer Center,

58 rue Montalembert,

63011 Clermont-Ferrand, France

F. Kwiatkowski

Department of Medical Research and Biostatistics,

Jean Perrin Cancer Center,

58 rue Montalembert,

63011 Clermont-Ferrand, France

B. Rabischong $(\bowtie)$

1, Place Lucie Aubrac,

63003 Clermont-Ferrand CEDEX 1, France

e-mail: brabischong@chu-clermontferrand.fr hospital stay was 5 days. The mean number of lymph nodes removed was 10 (2-25). Lymphadenectomy was considered not feasible in 20 cases $(12.9 \%)$ due to technical difficulties. Intraoperative and postoperative complications were seen in $11(5.6 \%)$ and 13 (6.6\%) women, respectively. Histopathological results led to upstaging in $11.6 \%$ of cases. After a mean follow-up of 74.8 months (14-204 months), 5-year causespecific and disease-free survival rates were $93.2 \%$ and $89.3 \%$, respectively. Twenty-one (10.6\%) patients developed recurrences. No port site metastases were identified. Laparoscopic management of EC is feasible, reproducible and does not worsen patient prognosis. It allows comprehensive surgical staging and the option of lymphadenectomy in a single surgical procedure without compromising the oncological radicality required. Our results show minimal morbidity and similar long-term outcomes than those obtained by laparotomy in the literature.

Keywords Endometrial cancer · Laparoscopy $\cdot$ Long-term follow-up · Survival

\section{Background}

Endometrial cancer (EC) is the most common gynaecological malignancy in developed countries, with more than 40,000 cases estimated to be diagnosed in 2009 in the USA [1] and 5,800 new cases diagnosed in 2005 in France [2].

Most women with EC develop postmenopausal bleeding, facilitating early diagnosis. Currently, more than $70 \%$ of cases are diagnosed whilst the tumour is confined to the uterus (clinical stage I) [3]. In such cases, surgery is the primary treatment.

According to the International Federation of Gynecology and Obstetrics (FIGO) [4], the staging surgery includes 
peritoneal washings, total hysterectomy and bilateral salpingo-oophorectomy. Although pelvic and para-aortic lymphadenectomy are recommended [5], they remain controversial.

In most centres worldwide, this surgical staging is more commonly performed via a midline vertical infraumbilical incision. Since the early 1990s, all the steps required for a comprehensive surgical staging are feasible by laparoscopy [6-10].

After these earliest reports [11-13], several retrospective studies [14-25] and recent trials [26-33] have demonstrated that laparoscopic staging of EC is feasible and safe, and results in shorter hospital stays and improved quality of life. Despite these established short-term advantages, there is no agreement about the survival benefit of laparoscopic staging procedures. The main reason for this is that survival data from well-designed prospective studies remain insufficient due to short-term follow-up [34]. Therefore, even if long-term outcomes after laparoscopic staging seem to be comparable to abdominal staging [18-22], they are not well documented yet.

The purpose of this study was to present our experience and both surgical and oncological outcomes for a large series of patients with early-stage EC managed completely via laparoscopy with a long-term follow-up.

\section{Patients and methods}

The medical records of 207 consecutive patients with earlystage (clinical stage I) EC who underwent laparoscopic staging at Clermont-Ferrand University Hospital and Jean Perrin Cancer Centre between February 1990 and December 2005 were retrospectively reviewed. Cases were identified from databases of both centres. Institutional Review Board exemption was granted by both centres because of the retrospective nature of this study.

Data collected included patient age, parity, menopausal status, body mass index (BMI), operating time, conversion to laparotomy, blood transfusion, intraoperative and postoperative complications, hospital stay, histological grade, number of lymph nodes yielded, surgical stage (FIGO 1988), adjuvant therapy, duration of follow-up and development of disease recurrence, site of recurrence or death.

It should be noted that although the FIGO staging was changed in 2009 [35], this change occurred after the creation of our database. Therefore, all our patients were staged and managed according to the old system. Moreover, most studies of laparoscopic management of EC, including the most recent trials [32-34], are based on the old system. Additionally, since no prognostic difference between the two systems for stage I EC has been noted [36], the old system is used in this report, unless otherwise stated.
Preoperative workup included pelvic examination, chest $\mathrm{X}$-ray, standard preoperative blood analysis and abdominopelvic MRI in most of the cases.

We offered laparoscopy as first-line treatment to all patients, and during the study period, we performed primary laparotomy only in patients for whom laparoscopic approach was contraindicated.

Contraindications for laparoscopy included: severe cardiopulmonary disease precluding the Trendelenburg position, anaesthetic contraindication for pneumoperitoneum, limited vaginal access and/or a bulky uterus where vaginal removal might require morcellation, presence of gross adenopathies at MRI (more advanced disease is suspected) and severe obesity $(B M I \geq 40)$ in the first 4 years of the study period. Previous laparotomy was not considered a contraindication for laparoscopy.

In all cases, laparoscopy started with a meticulous inspection of all pelvic and abdominal structures. In the event of evidence of peritoneal spread, we converted to laparotomy for completion of debulking and staging. The laparoscopic procedure included: peritoneal washing, total laparoscopic hysterectomy with bilateral salpingo-oophorectomy (TLH/ $\mathrm{BSO}$ ) and pelvic \pm para-aortic lymphadenectomy according to the results of frozen section or preoperative histology. Operating times were recorded from the creation of the pneumoperitoneum to skin closure.

Pelvic lymphadenectomy was performed for all women with myometrial invasion, grade 3 tumours and those with high-risk histology (e.g. papillary serous or clear cell adenocarcinoma; Fig. 1).

Our technique of TLH/BSO was described previously [37]. To display vaginal fornices and uterine vessels, we routinely used a uterine manipulator (Clermont-Ferrand, Karl Storz, Tuttlingen, Germany) with a smooth tip (no screw thread) specially designed for oncological purposes. Although the coagulation of the tubes before uterine cannulation is not a systematic practice in our department, it was made in some cases according to surgeon preference.

Briefly, pelvic lymphadenectomy consisted of complete skeletonization of common, internal and external iliac vessels and harvesting of all fatty and lymphatic tissue above and below the obturator nerve. Nodes yielded were routinely retrieved in an endoscopic bag and sent to the pathologist for frozen section. Para-aortic lymphadenectomy extended to the renal vessels was performed only if the pelvic nodes were shown to be involved at frozen section (Fig. 1).

All surgeries were performed by 11 surgeons who were assisted by residents or fellows.

Adjuvant treatment was discussed together with radiotherapists, pathologists, and medical oncologists in a multidisciplinary meeting according to the protocol shown in Fig. 2. Adjuvant whole pelvic radiation \pm brachytherapy 
Fig. 1 Management protocol followed during the whole study period

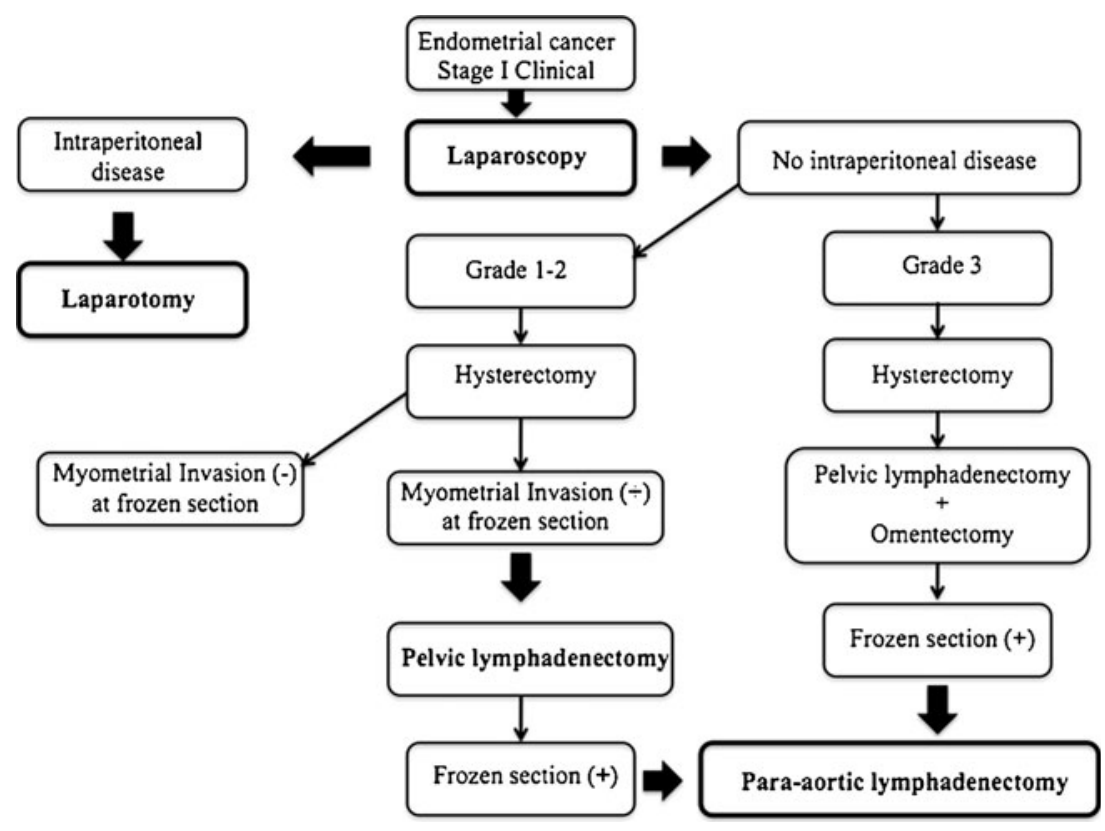

was recommended for all patients with grade 3 tumours and for those with surgical stage Ic or IIIa (positive cytology). Vaginal cuff brachytherapy was prescribed for patients with stage Ib grade 1/2. Patients with IIIa (adnexal involvement) and those with more advanced disease received extended field pelvic radiation and, in some cases, chemotherapy.

Follow-up visits were scheduled 1 month after surgery and then every 3 months for the first 2 years, and every 6 months thereafter. Recurrence-free and overall survival were estimated using Kaplan-Meier analysis, considering relapse or death as censoring events, respectively.

Data processing and statistical analysis were performed with SAS statistical software V8.02 (SAS Institute, Cary, $\mathrm{NC}$, USA). Statistical significance was established at $p<0.05$.

\section{Results and findings}

Among 207 patients with clinical stage I EC managed by laparoscopy, $52(25.1 \%)$ were obese $\left(\mathrm{BMI} \geq 30 \mathrm{~kg} / \mathrm{m}^{2}\right), 36$ $(17.3 \%)$ were nulliparous, and $56(27 \%)$ were $\geq 70$ years old. Patient characteristics and clinical data are summarised in Table 1.

The laparoscopic procedure could successfully be completed in $198(95.6 \%)$ patients, but it was converted to laparotomy in nine $(4.3 \%)$ patients.

Reasons for conversion were the following: extrauterine/ intraperitoneal disease $(n=4)$, several pelvic and intraperitoneal adhesions precluding pelvic visualisation $(n=2)$, severe subcutaneous emphysema and uncontrollable hypercapnia after hysterectomy (converted for lymphadenectomy, $n=1$ ),
Fig. 2 Postoperative management and different adjuvant therapies administered during the study period according to surgical stage and grade

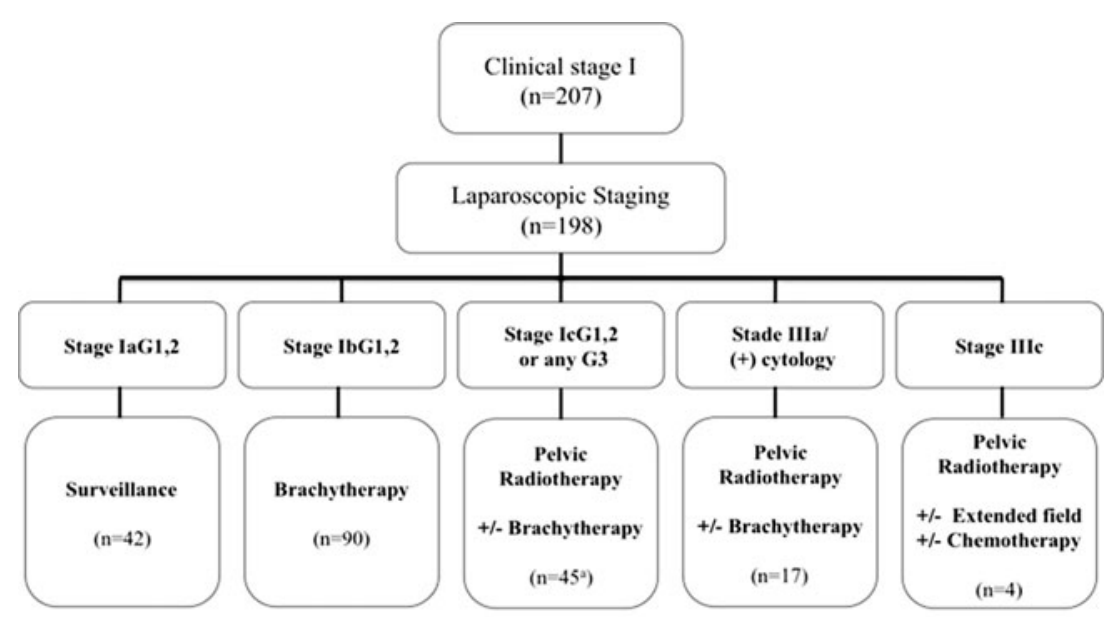

"Included 1 patient with stage $\mid \mathrm{IaG} 1$, and one with stage IIbGI 
Table 1 Clinical characteristics $(n=207)$

\begin{tabular}{ll}
\hline Mean age (range) & 63 years $(36-88)$ \\
Age $\geq 70$ years & $56(27 \%)$ \\
Mean BMI $\left(\mathrm{kg} / \mathrm{m}^{2}\right.$, range) & $26.2(16-56)$ \\
Obesity $(\mathrm{BMI} \geq 30)$ & $52(25.1 \%)$ \\
Nulliparity & $36(17.3 \%)$ \\
Postmenopausal status & $184(88.8 \%)$ \\
\hline
\end{tabular}

failure of pneumoperitoneum creation $\left(B M I=32 \mathrm{~kg} / \mathrm{m}^{2}\right.$, previous bowel resection, $n=1$ ) and difficult exposure due to morbid obesity $\left(\mathrm{BMI}=56 \mathrm{~kg} / \mathrm{m}^{2}, n=1\right)$. These patients were excluded from the analysis.

Pelvic node dissection was performed according to our protocol in $87.1 \%$ of cases. The procedure was deemed not feasible in $20(12.9 \%)$ cases because of morbid obesity $(n=7)$, inadequate ventilation due to pneumoperitoneum and Trendelenburg position $(n=7)$, several adhesions attributed to previous surgery $(n=2)$, and gas embolism $(n=1)$.

Three patients underwent para-aortic lymphadenectomy. For the first case, this was because of positive pelvic nodes at frozen section. The final histology reported three of ten metastatic para-aortic nodes. The second case was a patient with a clear cell tumour in which para-aortic lymphadenectomy was decided by the surgeon and eight negative para-aortic nodes were identified. The third case of lymph node dissection extended to the para-aortic chains was due to a false positive result of frozen section (endosalpingiosis).

Operative and postoperative complications occurred in $11(5.6 \%)$ and $13(6.6 \%)$ patients, respectively.

The mean operative time was 173.2 min (range 70$300 \mathrm{~min}$ ) for TLH and pelvic lymphadenectomy, including the time waiting for frozen section evaluation. The mean length of hospital stay was 5 days (range 2-16 days). Surgical outcomes and complications are shown in Table 2.

Definitive surgical stage and grade are shown in Table 3. As a result of surgical staging, 23 patients (11.6\%) were upstaged. Interestingly, there were two patients with stage IIIc tumours and positive pelvic lymph nodes for whom para-aortic lymphadenectomy was not performed because pelvic lymph nodes were negative at frozen section.

Reasons for upstaging were as follows: pelvic and/or para-aortic nodal metastases $(n=3)$, positive cytology $(n=13)$, adnexal metastases $(n=3)$ or both $(n=2)$. Two patients were upstaged due to cervical involvement. Adjuvant therapy was administered to 156 patients (Fig. 2). The mean follow-up was 74.8 months (range 14204 months). At the last follow-up (March 2010), 21 $(10.6 \%)$ women had recurrences, with a median recurrence interval of 35 months (range 6-143 months). No port site recurrences occurred in this series. Unexpectedly, one patient presented a delayed recurrence at 143 months after surgery. The sites of recurrence are summarised in Table 4. In order to be honest, we included among the recurrences two patients who probably had metastatic disease at the time of primary surgery. In these cases, preoperative evaluation could have led to understaging the disease (stage $>$ I), given recurrence site and time since surgery (Table 4). Thirteen patients died from recurrent disease. Among patients with surgical stage I, one patient who had stage Ib clear cell carcinoma developed an early peritoneal recurrence 7 months after surgery. She died 24 months later from peritoneal carcinomatosis.

Overall and cause-specific survival rates were $88.9 \%$ and $93.2 \%$, respectively ( $p=0.07$, NS; Fig. $3 \mathrm{a}$ ). The disease-free 5-year survival rate was $89.3 \%$ (Fig. 3b).

\section{Discussion}

Despite its retrospective design, this study remains an interesting data source. With its large series of consecutive patients with early-stage EC treated by laparoscopy over a long period of 15 years, this study in fact provides significant information about long-term survival and complications for these patients.

Surgical approach of endometrial cancer: the feasibility of laparoscopy

In agreement with several previous studies [14-33], our data support the statement that laparoscopic approach is feasible, safe and reproducible, offering patients all the advantages of a minimally invasive technique. Therefore, it seems that the only weakness in laparoscopic staging of EC is the increased operative time [22, 26, 30, 32]. We think that this is a reasonable concession given the lower morbidity, shorter hospital stay and improvement in quality of life [31-33]. These are major issues in EC patients who are frequently elderly, obese and with comorbid conditions. It should be noted that even if the mean hospital stay in our series was longer than previous reports [14-17], this can be explained by the fact that during the first 4 years of the study, patients stayed in the hospital for longer because we were more apprehensive about this "new" procedure. Nowadays, most patients are discharged on the second day after TLH, or even earlier in selected cases [38].

Vaginal hysterectomy has been reported as a safe, simpler and faster technique with low morbidity for the treatment of stage I EC in obese and elderly patients and those with significant coexisting medical conditions for whom total abdominal hysterectomy might be difficult or risky [39, 40]. However, the major objection to this approach is that it does not allow performing the complete 
Table 2 Summary of surgical outcomes and complications

\begin{tabular}{|c|c|c|c|c|}
\hline $\begin{array}{l}\text { Mean operative time } \\
(\mathrm{TLH}+\text { pelvic lymphadenectomy) }\end{array}$ & $173.2 \min (70-300)$ & Intraoperative complications & & $11(5.6 \%)$ \\
\hline Conversion rate & $9(4.3 \%)$ & Haemorrhage & 1 & Controlled vaginally \\
\hline Mean hospital stay (days) & $5(2-16)$ & Bladder injury & 1 & $\begin{array}{l}\text { Treated laparoscopically during } \\
\text { operation }\end{array}$ \\
\hline Mean return bowel activity (days) & $1.4(1-3)$ & Subcutaneous emphysema & 5 & $\begin{array}{l}\text { One case required late conversion } \\
\text { to perform lymphadenectomy }\end{array}$ \\
\hline Recurrence rate & $21(10.6 \%)$ & Gas embolism & 1 & $\begin{array}{l}\text { Operative time } 70 \mathrm{~min} \text {. Favourable } \\
\text { outcome }\end{array}$ \\
\hline Para-aortic lymphadenectomy & $3(1.5 \%)$ & Blood transfusion & 3 & \\
\hline Mean no. of pelvic nodes & $10(2-25)$ & Postoperative complications & & $13(6.6 \%)$ \\
\hline $\begin{array}{l}\text { Lymphadenectomies indicated } \\
\text { and not performed }\end{array}$ & $20(12.9 \%)$ & Hemoperitoneum & 1 & $\begin{array}{l}\text { Required laparotomy and blood } \\
\text { transfusion } 48 \mathrm{~h} \text { after surgery }\end{array}$ \\
\hline Positive cytology & $15(7.6 \%)$ & Pulmonary embolism & 1 & Discharged in good conditions \\
\hline Upstaged patients & $23(11.6 \%)$ & Vesicovaginal fistula & 1 & $\begin{array}{l}3 \text { months after surgery. Managed } \\
\text { laparoscopically }\end{array}$ \\
\hline Cause-specific survival & $93.2 \%$ & Intestinal sub-oclussion & 1 & $\begin{array}{l}\text { Requiring readmission and medical } \\
\text { treatment } 3 \text { weeks after surgery }\end{array}$ \\
\hline Median recurrence-free interval & 35 months & Phlebitis & 2 & \\
\hline Mean follow-up & 74.8 months & Port site hernia & 1 & \\
\hline Overall survival & $88.9 \%$ & Obturator neuropathy & 3 & Resolved spontaneously. \\
\hline Disease-free survival & $89.3 \%$ & Lymphedema/Lymphocyst & 2 & Resolved spontaneously. \\
\hline Adjuvant therapy & $156(78.8 \%)$ & Vaginal cuff dehiscence & 1 & $\begin{array}{l}\text { Previous radiotherapy. Cuff } \\
\text { dehiscence } 6 \text { years after } \\
\text { surgery. Re-closure without } \\
\text { complications }\end{array}$ \\
\hline
\end{tabular}

surgical staging recommended by FIGO [4] to be carried out. Moreover, inspection of the abdominal cavity and peritoneal washings are not possible and, frequently, the ovaries cannot be removed [39].

In this study, more than $50 \%$ of the women were elderly or obese. We have shown that laparoscopy is an adequate approach for these patients since all FIGO guidelines with regard to surgical staging can be met by laparoscopy.

During the study period, our surgical technique underwent no major changes and the complication rate remained lower than reported in previous studies [41] despite the higher number of surgeons. This is very important since it

Table 3 Distribution of patients according to stage and histological grade

\begin{tabular}{|c|c|c|c|}
\hline FIGO 1988 surgical stage & No. of patients $(\%)$ & Detail (\%) & FIGO 2009 surgical stage \\
\hline Ia & $43(21.7)$ & & Stage Ia: $164(82.8 \%)$ \\
\hline $\begin{array}{l}\mathrm{Ib} \\
\mathrm{Ic}\end{array}$ & $\begin{array}{l}96(48.5) \\
36(18.2)\end{array}$ & & Stage Ib: $36(18.1 \%)$ \\
\hline $\begin{array}{l}\text { IIa } \\
\text { IIb }\end{array}$ & $\begin{array}{l}1(0.5) \\
1(0.5)\end{array}$ & & Stage II: $1(0.5 \%)$ \\
\hline IIIa & $18(9.1)$ & $\begin{array}{l}\text { Positive cytology: } 13(6.6) \\
\text { Adnexal invasion: } 3(1.5) \\
\text { Both: } 2 \text { (1) }\end{array}$ & Stage IIIa: 5 (2.5\%) \\
\hline IIIc & $3(1.5)$ & & $\begin{array}{l}\text { Stage IIIc1: } 2(1 \%) \\
\text { Stage IIIc2: } 1(0.5 \%)\end{array}$ \\
\hline \multicolumn{4}{|l|}{ Grade } \\
\hline $\begin{array}{l}1 \\
2 \\
3\end{array}$ & $\begin{array}{r}154(77.3) \\
24(12.1) \\
21(10.6)\end{array}$ & & \\
\hline
\end{tabular}


Table 4 Recurrence site and time to recurrence among 21 patients who relapsed

\begin{tabular}{|c|c|c|c|c|}
\hline Case & 1988 FIGO stage/grade & Recurrence site(s) & Time to recurrence (months) & Status \\
\hline 1 & IbG3 (clear cell) & Peritoneal carcinomatosis & 7 & Deceased \\
\hline 2 & IIIaG3, $(+)$ cytology, $(+)$ adnexa & Vagina & 143 & Alive \\
\hline 3 & IIaG1 & Vagina + central pelvis & 58 & Alive \\
\hline 4 & IcG1 & Aortic lymph nodes + liver + lungs & 61 & Alive \\
\hline 5 & IIIaG1, $(+)$ cytology & Central pelvis + bone & 12 & Deceased \\
\hline 6 & IIIaG1, $(+)$ cytology & Vagina + lungs & 9 & Deceased \\
\hline 7 & IcG1 & Liver + lungs & 84 & Alive \\
\hline 8 & IbG1 & Lungs & 45 & Deceased \\
\hline 9 & IIIaG1, $(+)$ cytology & Peritoneum & 24 & Deceased \\
\hline 10 & IbG1 & Central pelvis & 42 & Deceased \\
\hline 11 & $\mathrm{IaG} 1$ & Vagina & 22 & Alive \\
\hline 12 & $\mathrm{IbG} 2$ & Lungs & 37 & Deceased \\
\hline 13 & IIIaG1, $(+)$ cytology & Bone & 15 & Alive \\
\hline 14 & IIIaG3, $(+)$ cytology & Liver + lungs & 13 & Deceased \\
\hline $15^{\mathrm{a}}$ & IIIaG3 (clear cells), $(+)$ adnexa & Aortic lymph nodes + liver & 6 & Deceased \\
\hline $16^{\mathrm{a}, \mathrm{b}}$ & IIIcG1 & Aortic lymph nodes & 6 & Alive \\
\hline 17 & $\mathrm{IaG} 1$ & Vagina + peritoneum & 13 & Deceased \\
\hline 18 & IcG1 & Central pelvis + aortic lymph nodes + lungs & 29 & Deceased \\
\hline 19 & IbG3 & Central pelvis & 45 & Alive \\
\hline 20 & IcG3 & Peritoneum & 22 & Deceased \\
\hline 21 & IIIaG3, $(+)$ cytology & Peritoneum + liver + lungs & 16 & Deceased \\
\hline
\end{tabular}

${ }^{a}$ Probably presence of metastatic disease at time of surgery. Clinically understaged

${ }^{\mathrm{b}}$ Para-aortic lymphadenectomy not performed. False (-) frozen section of pelvic nodes

underlines the importance of using a standardised surgical technique in order to reduce complications and achieve procedure reproducibility [42].

Despite the claim that use of uterine cannulation is not necessary [30] and that it may led to dissemination of tumoral cells $[43,44]$, there is no evidence that uterine manipulation during laparoscopy increases the risk of cell spillage in the pelvic cavity [27, 28, 45]. To date, the prognostic importance of isolated positive cytology remains uncertain [46]. In fact, the new FIGO staging system deleted cytology as a variable dictating more advanced disease [35]. In this study, the rate of positive cytology and vaginal recurrence was comparable with those reported in previous studies in which patients were treated by laparotomy [47] or those in which TLH was performed without uterine cannulation [48]. Moreover, several studies comparing laparotomy with laparoscopy have shown that the rate of positive cytology was identical between the groups [41] even if the uterus was cannulated [24, 27]. Furthermore, in our experience, the uterine manipulator is essential
Fig. 3 a Overall and causespecific 5-year survival rates projected by Kaplan-Meier curves (log-rank test, $p=0.07$, NS). b Disease-free 5-year survival curve
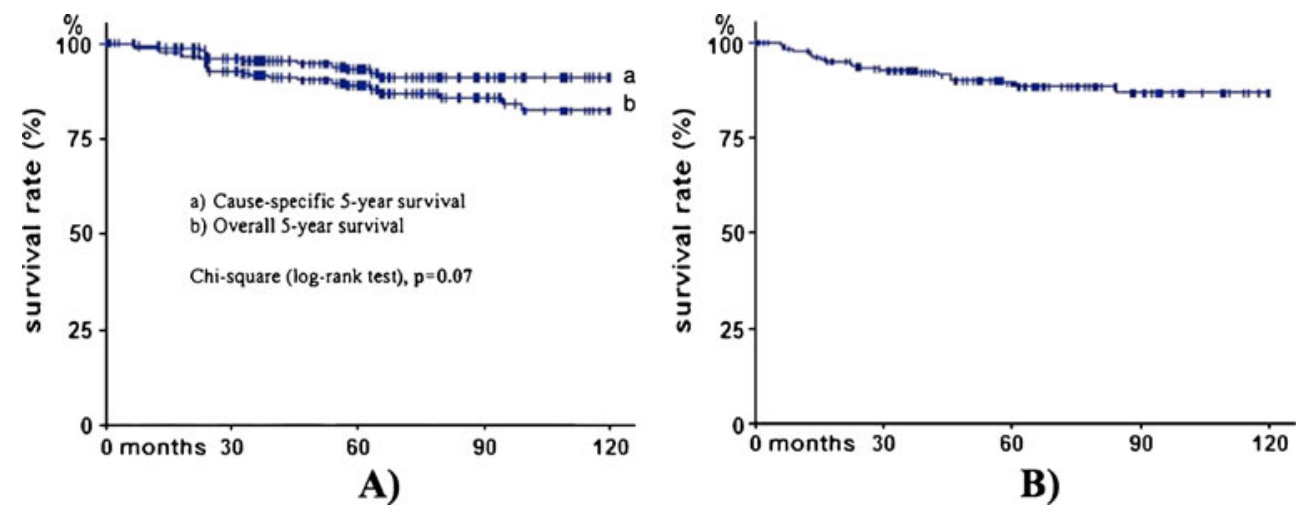
to improve exposure and prevent ureteral complications [37]. This is important since impaired exposure is a major reason for conversion [32], especially in obese women [49].

The rate of conversion to laparotomy was $4.3 \%$ in this series. It compares favourably with previous reports [24, $31,32]$ and is consistent with the conversion rates reported for single-centre studies $(<10 \%)$ [15, 20, 23] Unexpectedly, the recently published LAP-2 multicentric randomised controlled trial (RCT) [32] reported a conversion rate of $26 \%$. This surprisingly high rate of conversion is probably more representative of the reality, without the bias of a specialised centre. However, it may be influenced by the higher prevalence of obesity among women in the USA compared with Europe [50] and the need for comprehensive surgical staging (including pelvic and para-aortic lymphadenectomy) to meet the study protocol [32].

These features make the LAP-2 protocol not fully applicable in many centres around the world where systematic pelvic and para-aortic lymphadenectomy is not the standard treatment for early-stage EC [22, 24, 27, 28, $41,51]$.

Lymphadenectomy and endometrial cancer: the controversy

Despite the fact that lymphadenectomy is recommended as a standard component of surgical staging of EC $[4,5]$ and that there is agreement about its prognostic value, it remains a variable practice from institution to institution. Surveys of major gynaecological cancer centres demonstrate these differing approaches to management, with $54 \%$ of American centres [52] and 24\% of centres in Western Europe [53] performing systematic lymphadenectomy for all women. Therefore, the reality is that about $50 \%$ of women still do not undergo lymphadenectomy at the time of their primary surgery [54].

The therapeutic benefit of lymphadenectomy is based on several retrospective studies that reported a significant survival advantage for patients undergoing lymph node dissection [54-58]. Conversely, and according to recent data, the surgical strategy for management of EC could undergo major changes. Two randomised trials have concluded that there is no benefit in performing systematic lymphadenectomy for clinical stage I EC in terms of overall, disease-specific and recurrence-free survival [59, 60]. In this context, older studies [61, 62] have demonstrated that in low-risk patients (endometrioid histology, grade 1 or 2 , and without or with tumours invading $<50 \%$ of the myometrium), the risk of nodal metastases is negligible. Furthermore, in the absence of positive pelvic lymph nodes or other risk factors associated with a poor prognosis, the probability of para-aortic lymph node metastases is extremely low $[62,63]$. In this study, the number of patients with positive pelvic nodes was lower than in previous reports $[23,26,59,60,64]$, but this could be explained by the fact that most of the patients in our series had low-risk tumours.

Recently, Mariani et al. [65] analysed the extension of lymphatic spread among 422 patients with clinical stage I EC. The authors reported that in patients with high-risk disease, the rate of lymphatic metastases above the inferior mesenteric artery was $16 \%$, even with negative pelvic nodes. On the contrary, a recent paper including 1,942 patients showed that the risk of isolated para-aortic metastases was $1 \%$, even with high-risk tumours, continuing the controversy concerning this issue [66]. In this study, most patients had low-risk tumours, and only three women underwent para-aortic lymphadenectomy. Therefore, the numbers are insufficient to draw any conclusion on the risk of isolated para-aortic metastases.

Based on the growing evidence suggesting that lymphadenectomies are not appropriate for low-risk patients [67] and the fact that the procedure is not totally free of complications [67, 68], the most rational approach is to adapt the indication of lymphadenectomy according to the patient's characteristics (age, performance status, comorbid conditions) and the histological characteristics of the tumour at preoperative biopsy or frozen section.

In our experience, as in others $[69,70]$, frozen section is a reliable method for triage of patients for lymphadenectomy, with a low rate of false-negative results.

Today, the therapeutic benefits of lymphadenectomy are still matter of debate, especially in early-stage disease [71]. In addition, there are still many questions to be answered about the role and extension of lymphadenectomy in EC. In this setting, the sentinel lymph node technique seems promising since it could clarify the current controversies regarding lymphatic dissemination of EC in the future [72, 73], although further studies are needed before it is put into clinical practice.

Although in our series only three of the patients with higher risk of recurrence underwent complete surgical staging including para-aortic lymphadenectomy, several randomised trials $[74,75]$ have demonstrated the safety of adjuvant radiotherapy in these patients despite the lack of comprehensive staging.

To date, with or without lymphadenectomy, the role of laparoscopy in the management of EC is established and the advantages of minimally invasive techniques are well known. Therefore, if lymphadenectomy proves to be necessary it should be attempted using a minimally invasive approach. This is very interesting since in our experience, and in agreement with several reports [32, 49], lymphadenectomy is the limiting step when performing laparoscopic staging due to impaired exposure.

This apparent "conflict" between a minimally invasive procedure and a comprehensive staging including complete lymphadenectomy could be resolved with the use of other 
techniques, such as the extraperitoneal laparoscopic approach [76] or robotic-assisted laparoscopy [77], in order to overcome the limitations of conventional laparoscopy.

Long-term results of laparoscopy in endometrial cancer patients

To be accepted as the gold standard, a surgical procedure must be feasible, effective, reproducible and safe. In addition, when treating cancer patients, it is mandatory to not compromise standard survival outcomes.

Several retrospective studies have shown no difference in survival and recurrence rates between laparotomy and laparoscopy; however, these studies are limited by their sample size and short-term follow-up [21-25]. To date, three RCTs have included survival data [26-28]. None of these studies have demonstrated any significant difference between laparoscopy or laparotomy with respect to recurrence, disease-free and overall survival. These trials lacked the power to prove this hypothesis, however, and only one of them has a mean follow-up $>4$ years [28].

Recently, Walker et al. [34] released initial survival data from the LAP-2 study conducted by the GOG at the 41st Annual Meeting of the Society of Gynecologic Oncologists. As expected, the authors showed that the 3-year overall survival was $89.8 \%$ in the laparoscopy group and $89.9 \%$ in the laparotomy group. They concluded that laparoscopy should be considered the standard for treatment for EC. We agree with these conclusions, but it is important to note that even if the sample size of the study was appropriate to address this issue, the follow-up is still too short. In this context, we think that there is still place for large retrospective series such as this one to support these conclusions. Although it is a retrospective study, its major strength is the long-term follow-up. Interestingly, in this and other studies with a longer follow-up, more than 30\% of the recurrences reported occurred after 36 months [28].

In our study, the recurrence rate and disease-free 5-year survival were $10.6 \%$ and $89.3 \%$, respectively, and are comparable with survival and recurrence data obtained by laparotomy [5]. Our results support the oncological safety of the laparoscopic approach. Therefore, to draw definitive conclusions from RCT, all that is needed is time. If the good results already published are confirmed in a few years, laparoscopy will become the gold standard technique for the management of early-stage EC.

\section{Conclusion}

Although long-term results of recent RCTs are still immature, available data demonstrate that the results of laparoscopy are equivalent or better than those achieved with laparotomy. From the data presented, we think that equivalent rates for both disease-free and overall survival can be expected. Therefore, after adequate training, laparoscopy should be preferred over laparotomy for the management of early-stage EC.

Declaration of interest The authors have no conflicts of interest to declare.

\section{References}

1. Jemal A, Siegel R, Ward E, Hao Y, Xu J, Thun MJ (2009) Cancer statistics, 2009. CA Cancer J Clin 59:225-249

2. Belot A, Grosclaude P, Bossard N, Jougla E, Benhamou E, Delafosse $\mathrm{P}$ et al (2008) Cancer incidence and mortality in France over the period 1980-2005. Rev Epidemiol Sante Publique $56: 159-175$

3. Creasman WT, Odicino F, Maisonneuve P, Quinn MA, Beller U, Benedet JL et al (2006) Carcinoma of the corpus uteri. FIGO 6th Annual Report on the Results of Treatment in Gynecological Cancer. Int J Gynaecol Obstet 95(Suppl 1):S105-S143

4. Sheperd JH (1989) Revised FIGO staging for gynaecological cancer. Br J Obstet Gynaecol 96:889-892

5. ACOG Practice Bulletin (2005) Clinical management guidelines for obstetrician-gynecologists. Management of endometrial cancer. Obstet Gynecol 106:413-424

6. Reich H, DeCaprio J, McGlynn F (1989) Laparoscopic hysterectomy. J Gynecol Surg 5:213-215

7. Canis M, Mage G, Chapron C, Wattiez A, Pouly JL, Bruhat MA (1993) Laparoscopic hysterectomy. A preliminary study. Surg Endosc 7:42-45

8. Wattiez A, Raymond F, Canis M, Chapron C, Pouly JL, Mage G et al (1993) External iliac lymphadenectomy by celioscopy: surgical technique. Ann Chir 47:523-528

9. Childers JM, Hatch KD, Tran AN, Surwit EA (1993) Laparoscopic para-aortic lymphadenectomy in gynecologic malignancies. Obstet Gynecol 82:741-747

10. Querleu D (1993) Laparoscopic paraaortic node sampling in gynecologic oncology: a preliminary experience. Gynecol Oncol 49:24-29

11. Childers JM, Surwit EA (1992) Combined laparoscopic and vaginal surgery for the management of two cases of stage I endometrial cancer. Gynecol Oncol 45:46-51

12. Childers JM, Brezechffa PR, Hatch KD, Surwitt EA (1993) Laparoscopically assisted surgical staging (LASS) of endometrial cancer. Gynecol Oncol 51:33-38

13. Mage G, Bournazeau JA, Canis M, Glowaczower E, Masson FN, Raiga J et al (1995) Treatment of endometrial clinical stage I endometrial adenocarcinoma by laparoscopic surgery. Seventeen cases. J Gynecol Obstet Biol Reprod (Paris) 24:485-490

14. Hidlebaugh DA, Orr RK (1997) Staging endometrial carcinoma. Clinical and financial comparison of laparoscopic and traditional approaches. J Reprod Med 42:482-488

15. Gemignani ML, Curtin JP, Zelmanovich J, Patel DA, Venkatraman E, Barakat RR (1999) Laparoscopic assisted vaginal hysterectomy for endometrial cancer: clinical outcomes and hospital charges. Gynecol Oncol 73:5-11

16. Holub Z, Jabor A, Bartos P, Eim J, Urbánek S, Pivovarniková R (2002) Laparoscopic surgery for endometrial cancer: long term results of a multicentric study. Eur J Gynaecol Oncol 23:305-310 
17. Occelli B, Samouelian V, Narducci F, Leblanc E, Querleu D (2003) The choice of approach in the surgical management of endometrial carcinoma: a retrospective serie of 155 cases. Bull Cancer 90:347-355

18. Magrina JF, Mutone NF, Weaber AL, Magtibay PM, Fowler RS, Cornella JL (1999) Laparoscopic hysterectomy with bilateral salpingo-oophorectomy for endometrial cancer: morbidity and survival. Am J Obstet Gynecol 181:376-381

19. Eltabbakh GH (2002) Analysis of survival after laparoscopy in women with endometrial carcinoma. Cancer 95:1894-1901

20. Kuoppala T, Tomas E, Heinonen PK (2004) Clinical outcomes and complications of laparoscopic surgery compared with tradicional surgery in women with endometrial cancer. Arch Gynecol Obstet 270:25-30

21. Magrina JF, Weaber AL (2004) Laparoscopic treatment of endometrial cancer: five-year recurrence and survival rates. Eur J Gynaecol Oncol 25:439-441

22. Zapico A, Fuentes P, Grassa A, Arnanz F, Otazua J, Cortés-Prieto J (2005) Laparoscopic-assisted vaginal hysterectomy versus abdominal hysterectomy in stage I and II endometrial cancer. Operating data, follow up and survival. Gynecol Oncol 98:222-227

23. Cho YH, Kim DY, Kim YM, Kim YT, Nam JH (2007) Laparoscopic management of early uterine cancer: 10-year experience in Asan Medical Center. Gynecol Oncol 106:585-590

24. Nezhat F, Yadav J, Rahaman J, Gretz H, Cohen C (2008) Analysis of survival after laparoscopic management of endometrial cancer. J Minim Invasive Gynecol 15:181-187

25. Obermair A, Manolitsas TP, Leung Y, Hammond IG, McCartney AJ (2004) Total laparoscopic hysterectomy for endometrial cancer: patterns of recurrence and survival. Gynecol Oncol 92:789-793

26. Malzoni M, Tinelli R, Cosentino F, Perone C, Rasile M, Iuzzolino $\mathrm{D}$ et al (2009) Total laparoscopic hysterectomy versus abdominal hysterectomy with lymphadenectomy for early-stage endometrial cancer: a prospective randomized study. Gynecol Oncol 112:126133

27. Tozzi R, Malur S, Koehler C, Schneider A (2005) Laparoscopy versus laparotomy in endometrial cancer: first analysis of survival of a randomized prospective study. J Minim Invasive Gynecol $12: 130-136$

28. Zullo F, Palomba S, Falbo A, Russo T, Mocciaro R, Tartaglia E et al (2009) Laparoscopic surgery vs laparotomy for early stage endometrial cancer: long-term data of a randomized controlled trial. Am J Obstet Gynecol 200(296):e1-e9

29. Zorlu CG, Simsek T, Ari ES (2005) Laparoscopy or laparotomy for the management of endometrial cancer. JSLS 9:442-446

30. Fram KM (2002) Laparoscopically assisted vaginal hysterectomy versus abdominal hysterectomy in stage I endometrial cancer. Int $\mathrm{J}$ Gynecol Cancer 12:57-61

31. Zullo F, Palomba S, Russo T, Falbo A, Costantino M, Tolino A et al (2005) A prospective randomized comparison between laparoscopic and laparotomic approach in women with early stage endometrial cancer: a focus on the quality of life. Am J Obstet Gynecol 193:1344-1352

32. Walker JL, Piedmonte MR, Spirtos NM, Eisenkop SM, Schlaerth JB, Mannel RS et al (2009) Laparoscopy compared with laparotomy for comprehensive surgical staging of uterine cancer: Gynecologic Oncology Group Study LAP2. J Clin Oncol 27:5331-5336

33. Kornblith AB, Huang HQ, Walker JL, Spirtos NM, Rotmensch J, Cella D (2009) Quality of life of patients with endometrial cancer undergoing laparoscopic International Federation of Gynecology and Obstetrics staging compared with laparotomy: a Gynecologic Oncology Group Study. J Clin Oncol 27:5337-5342

34. Walker JL, Piedmonte MR, Spirtos NM, Eisenkop SM, Spiegel G, Mannel RS et al (2010) Recurrence and survival after randomization to laparoscopy versus laparotomy for comprehensive surgical staging of uterine cancer: Gynecologic Oncology Group Study LAP2. 2010 SGO 41st Annual Meeting, Abstract LBA1

35. Creasman W (2009) Revised FIGO staging for carcinoma of the endometrium. Int J Gynaecol Obstet 105:109

36. Lewin S, Herzog T, Barrena Medel N, Deutsch I, Sun X, Burke W et al (2010) Comparative performance of the new versus old FIGO staging system for endometrial cancer. Gynecol Oncol 116(Suppl 1):6-7, Abstract 10

37. Wattiez A, Soriano D, Cohen SB, Nervo P, Canis M, Botchorishvili R et al (2002) The learning curve of total laparoscopic hysterectomy: comparative analysis of 1647 cases. J Am Assoc Gynecol Laparosc 9:339-345

38. de Lapasse C, Rabischong B, Bolandard F, Canis M, Botchorishvili $\mathrm{R}$, Jardon $\mathrm{K}$ et al (2008) Total laparoscopic hysterectomy and early discharge: satisfaction and feasibility study. J Minim Invasive Gynecol 15:20-25

39. Chan JK, Lin YG, Monk BJ, Tewari K, Bloss JD, Berman ML (2001) Vaginal hysterectomy as primary treatment of endometrial cancer in medically compromised women. Obstet Gynecol 97:707-711

40. Massi G, Savino L, Susini T (1996) Vaginal hysterectomy versus abdominal hysterectomy for the treatment of stage I endometrial adenocarcinoma. Am J Obstet Gynecol 174:1320-1326

41. Hahn HS, Kim HJ, Yoon SG, Kim WC, Choi HJ, Kim HS et al (2010) Laparoscopy-assisted vaginal versus abdominal hysterectomy in endometrial cancer. Int J Gynecol Cancer 20:102-109

42. Altgassen C, Possover M, Krause N, Plaul K, Michels W, Schneider A (2000) Establishing a new technique of laparoscopic pelvic and para-aortic lymphadenectomy. Obstet Gynecol 95:348-352

43. Lim S, Kim HS, Lee KB, Yoo CW, Park SY, Seo SS (2008) Does the use of an uterine manipulator with an intrauterine balloon in total laparoscopic hysterectomy facilitate tumor cell spillage into the peritoneal cavity in patients with endometrial cancer? Int $\mathrm{J}$ Gynecol Cancer 18:1145-1149

44. Sonoda Y, Zerbe M, Smith A, Lin O, Barakat RR, Hoskins WJ (2001) High incidence of positive peritoneal cytology in low-risk endometrial cancer treated by laparoscopically assisted vaginal hysterectomy. Gynecol Oncol 80:378-382

45. Eltabbakh GH, Mount SL (2006) Laparoscopic surgery does not increase the positive peritoneal cytology among women with endometrial carcinoma. Gynecol Oncol 100:361-364

46. Wethington SL, Barrena Medel NI, Wright JD, Herzog JT (2009) Prognostic significance and treatment implications of positive peritoneal cytology in endometrial adenocarcinoma: unraveling a mystery. Gynecol Oncol 115:18-25

47. Turner DA, Gershenson DM, Atkinson N, Sneige N, Wharton AT (1989) The prognostic significance of peritoneal cytology for stage I endometrial cancer. Obstet Gynecol 74:775-780

48. Wong CK, Wong YH, Lo LS, Tai CM, Ng TK (2005) Laparoscopy compared with laparotomy for the surgical staging of endometrial carcinoma. J Obstet Gynaecol Res 31:286-290

49. Scribner DR Jr, Walker JL, Johnson GA, McMeelin DS, Gold MA, Mannel RS (2002) Laparoscopic pelvic and paraaortic lymph node dissection in the obese. Gynecol Oncol 84:426-430

50. Pischon T, Nöthlings U, Boeing H (2008) Obesity and cancer. Proc Nutr Soc 67:128-145

51. Ghezzi F, Cromi A, Uccella S, Siesto G, Giudici S, Serati M et al (2010) Laparoscopic versus open surgery for endometrial cancer: a minimum 3-year follow-up study. Ann Surg Oncol 17:271-278

52. Maggino T, Romagnolo C, Landoni F, Sartori E, Zola P, Gardducci A (1998) An analysis of approaches to the management of endometrial cancer in North America: a CTF study. Gynecol Oncol 68:274-279

53. Maggino T, Romagnolo C, Zola P, Sartori E, Landoni F, Gardducci A (1995) An analysis of approaches to the treatment 
of endometrial cancer in western Europe: a CTF study. Eur J Cancer 31A:1993-1997

54. Smith DC, Macdonald OK, Lee CM, Gaffney DK (2008) Survival impact of lymph node dissection in endometrial carcinoma: a surveillance, epidemiology, and end results analysis. Int J Gynecol Cancer 18:255-261

55. Kilgore LC, Partridge EE, Alvarez RD, Austin JM, Shingleton HM, Noojin F 3rd et al (1995) Adenocarcinoma of the endometrium: survival comparisons of patients with and without pelvic node sampling. Gynecol Oncol 56:29-33

56. Mohan DS, Samuels MA, Selim MA, Shalodi AD, Ellis RJ, Samuels JR et al (1998) Long-term outcomes of therapeutic pelvic lymphadenectomy for stage I endometrial adenocarcinoma. Gynecol Oncol 70:165-171

57. Chan JK, Cheung MK, Huh WK, Osann K, Husain A, Teng NN et al (2006) Therapeutic role of lymph node resection in endometrioid corpus cancer: a study of 12,333 patients. Cancer 107:1823-1830

58. Todo Y, Kato H, Kaneuchi M, Watari H, Takeda M, Sakuragi N (2010) Survival effect of para-aortic lymphadenectomy in endometrial cancer (SEPAL Study): a retrospective cohort analysis. Lancet 375:1165-1172

59. ASTEC Study Group, Kitchener H, Swart AM, Qian Q, Amos C, Parmar MK (2009) Efficacy of systematic pelvic lymphadenectomy in endometrial cancer (MRC ASTEC trial): a randomised study. Lancet 373:125-136

60. Benedetti Panici P, Basile S, Maneschi F, Alberto Lissoni A, Signorelli M, Scambia G et al (2008) Systematic pelvic lymphadenectomy vs no lymphadenectomy in early-stage endometrial carcinoma: randomized clinical trial. J Natl Cancer Inst 100:1707-1716

61. Creasman WT, Morrow CP, Bundy BN, Homesley HD, Graham JE, Heller PG (1987) Surgical pathologic spread patterns of endometrial cancer: a Gynecologic Oncology Group study. Cancer 60:2035-2041

62. Boronow RC, Morrow CP, Creasman WT, Disaia PJ, Silverberg SG, Miller A (1984) Surgical staging in endometrial cancer: clinical-pathologic findings of a prospective study. Obstet Gynecol 63:825-832

63. Morrow CP, Bundy BN, Kurman RJ, Creasman WT, Heller P, Homesley HD (1991) Relationship between surgical pathological risk factors and outcome in clinical stage I and II carcinoma of the endometrium: a Gynecologic Oncology Group study. Gynecol Oncol 40:55-65

64. Chi DS, Barakat RR, Palayekar MJ, Levine DA, Sonoda Y, Alektiar K et al (2008) The incidence of pelvic lymph node metastasis by FIGO staging for patients with adequately surgically staged endometrial adenocarcinoma of endometrioid histology. Int J Gynecol Cancer 18:269-273

65. Mariani A, Dowdy SC, Cliby WA, Gostout BS, Jones MB, Wilson TO et al (2008) Prospective assessment of lymphatic dissemination in endometrial cancer: a paradigm shift in surgical staging. Gynecol Oncol 109:11-18

66. Abu-Rustum NR, Gomez JD, Alektiar KM, Soslow RA, Hensley ML, Leitao MM Jr et al (2009) The incidence of isolated paraaortic nodal metastasis in surgically staged endometrial cancer patients with negative pelvic lymph nodes. Gynecol Oncol 115:236-238

67. May K, Bryant A, Dickinson HO, Kehoe S, Morrison J (2010) Lymphadenectomy for the management of endometrial cancer. Cochrane Database Syst Rev 1:CD7585

68. Cragun JM, Havrilesky LJ, Calingaert B, Synan I, Secord AA, Soper JT et al (2005) Retrospective analysis of selective lymphadenectomy in apparent early-stage endometrial cancer. J Clin Oncol 23:3668-3675

69. Quinlivan JA, Petersen RW, Nicklin JL (2001) Accuracy of frozen section for the operative management of endometrial cancer. BJOG 108:798-803

70. Egle D, Grissemann B, Zeimet AG, Müller-Holzner E, Marth C (2008) Validation of intraoperative risk assessment on frozen section for surgical management of endometrial carcinoma. Gynecol Oncol 110:286-292

71. Seamon LG, Fowler JM, Cohn DE (2010) Lymphadenectomy for endometrial cancer: the controversy. Gynecol Oncol 117:6-8

72. Barranger E, Delpech Y, Coutant C, Dubernard G, Uzan S, Darai E (2009) Laparoscopic sentinel node mapping using combined detection for endometrial cancer: a study of 33 cases-is it a promising technique? Am J Surg 197:1-7

73. Abu-Rustum NR, Khoury-Collado F, Pandit-Taskar N, Soslow RA, Dao F, Sonoda Y et al (2009) Sentinel lymph node mapping for grade 1 endometrial cancer: is it the answer to the surgical staging dilemma? Gynecol Oncol 113:163-169

74. Creutzberg CL, van Putten WL, Koper PC, Lybeert ML, Jobsen JJ, Wárlám-Rodenhuis CC et al (2000) Surgery and postoperative radiotherapy versus surgery alone for patients with stage-1 endometrial carcinoma: multicentre randomised trial. PORTEC Study Group. Post Operative Radiation Therapy in Endometrial Carcinoma. Lancet 355:1404-1411

75. Nout RA, Smit VP, Putter H, Jürgenliemk-Schulz IM, Jobsen JJ, Lutgens LC et al (2010) Vaginal brachytherapy versus pelvic external bean radiotherapy for patients with endometrial cancer of high-intermediate risk (PORTEC-2): an open-label non-inferiority, randomised trial. Lancet 375:816-823

76. Dowdy SC, Aletti G, Cliby WA, Podratz KC, Mariani A (2008) Extra-peritoneal laparoscopic para-aortic lymphadenectomy-a prospective cohort study of 293 patients with endometrial cancer. Gynecol Oncol 111:418-424

77. Gehrig PA, Cantrell LA, Shafer A, Abaid LN, Mendivil A, Boggess JF (2008) What is the optimal minimally invasive surgical procedure for endometrial cancer staging in the obese and morbidly obese woman? Gynecol Oncol 111:41-45 